Research Article

\title{
Effective Factor Analysis for Chromium(VI) Removal from Aqueous Solutions and Its Application to Tunçbilek Lignite Using Design of Experiments
}

\author{
Âli Yurdun Orbak (iD) ${ }^{1}$ and İlkün Orbak ${ }^{2}$ \\ ${ }^{1}$ Industrial Engineering Department, Bursa Uludag University, Gorukle, 16059 Bursa, Turkey \\ ${ }^{2}$ Industrial Engineering Department, Maltepe University, Maltepe, 34857 Istanbul, Turkey
}

Correspondence should be addressed to Âli Yurdun Orbak; orbak@uludag.edu.tr

Received 27 September 2018; Revised 24 March 2019; Accepted 30 April 2019; Published 22 May 2019

Academic Editor: Mostafa Khajeh

Copyright () 2019 Âli Yurdun Orbak and İlkün Orbak. This is an open access article distributed under the Creative Commons Attribution License, which permits unrestricted use, distribution, and reproduction in any medium, provided the original work is properly cited.

\begin{abstract}
Poisonous heavy metals in air, water, and soil produce global environmental problems that are considerable threats to humankind. To meet the local and international guidelines for heavy metal release, companies often use different approaches, such as chemical precipitation, chelating agents, or activated carbon produced by adsorption. One of these heavy and toxic metals is chromium(VI). Chromium(VI) is commonly used in many applications, such as dye fixation in the textile industry or as an anticorrosive agent in paints. The aim of this paper is to explore the factors affecting the removal of one of these deadly heavy metals, chromium(VI), from aqueous solutions. For this purpose, activated carbon from Turkish Tunçbilek lignite is prepared with both chemical and physical activation methods to investigate the adsorption behavior of chromium(VI). The effects of initial chromium(VI) concentration, adsorption temperature, and $\mathrm{pH}$ on adsorption are studied using a design of experiments method with a full $2^{4}$ factorial design with center points. The Freundlich and Langmuir adsorption isotherms that are commonly used in chemical engineering are also applied both for predicting the amount of chromium(VI) adsorbed and confirming the validity and advantages of the obtained regression model. The results indicate that the design of experiments and regression can explain and support the design of new materials by using linear and physically meaningful equations instead of local nonlinear and empirical models that are usually insufficient. Additionally, three experiments were carried out in the liquid phase to test the activated carbon samples: chromium, chromium and sucrose, and chromium-sucrose-ion. A change in adsorption capacities of the activated carbon samples was observed. Sucrose was chosen for the experiments because it contains six carbon atoms in a slightly soluble structure. The results indicated that Tunçbilek lignite exhibits good adsorption capability.
\end{abstract}

\section{Introduction}

Heavy metal pollution is one of the environmental problems in the world today. The mixing of heavy metals with soil and water is dangerous. Industrial and municipal wastewaters contain a variety of metal ions that can damage aquatic life and human health [1-4]. Wastewater containing heavy metals derives from the chemical industry, metal coating facilities, mining facilities, cosmetics production, petrochemical applications, and cleaning product usage $[2,5]$. Heavy metals can be removed from wastewater by chemical precipitation, membrane filtration, ion exchange, solvent extraction, and adsorption methods $[3,4,6]$. The adsorption method has been used for water and wastewater for a long time to remove color, odor, and organic contaminants $[3,7]$. In comparison with the other methods, adsorption is the cheapest and most widely used process [8]. One of the most effective methods for removing organic and inorganic pollutants from industrial and urban wastes is liquid phase adsorption. On the other hand, activated carbon (AC) is an effective low-cost adsorbent. Physical and chemical sorption technologies have been used for many years to remove toxic metals from wastewater. In the literature, low-cost raw materials, such as leaf mold, peat moss, green algae, activated 
carbon fibers, coconut residues, rubber, wood, lignite, and rubber, have been studied $[2,3,8-14]$. However, the development of new, economical, and readily available effective absorbent materials is still necessary [15].

Despite having lower adsorption capacities than synthetic ion exchange materials for the removal of heavy metal ions from wastewater, the use of low-rank grade coals is widespread due to their lower cost $[16,17]$. Recently, the adsorption of metal ions on active carbon produced by lignite has been studied extensively [2, 17-22]. Lignite is abundant in Turkey and contains low ash and high carbon contents; therefore, it is a good raw material for activated carbon. Activated carbon is a carbon-based material, with a high content of carbon, existing in a large reserve and presenting difficulties in its evaluation. It is easily understood that our country has significant potential in this regard. Lignite is fuel, and Turkey's reserves of lignite are sufficient. Today, the use of lignite for energy purposes, especially for heating, has decreased considerably. In the future, lignite consumption will continue to drop. Therefore, the most efficient use of lignite reserves is essential. In this respect, lignite can represent an excellent raw material for the production of activated carbon and can be brought into the economy more efficiently. When we examine the characteristics of Tunçbilek lignite, the fixed carbon content is $55-70 \%$, volatile matter content is $35-40 \%$, density is $1-1.35 \mathrm{~g} / \mathrm{cm}^{3}$, and ash content is $5-6 \%$.

Chromium is widely used in the metallurgy industry as ferrochrome, ferro-silico-chromium, chromium compounds, exothermic chromium additives, other major chromium alloys, and chromium metal and has applications such as electroplating, water cooling, pulp production, and ore refinement. Hexavalent chromium (chromium(VI)) is a toxic substance for both plants and animals and is known to be carcinogenic. Therefore, chromium(VI) in wastewater must be regulated to below $0.1 \mathrm{mg} / \mathrm{L}$ by the U.S. EPA (see the web page of United States Environmental Protection Agency at http://www.epa.gov). In the Marmara Region, almost all of the surface waters are found to be polluted or very polluted as a result of the increase in the use of fertilizers and chemical drugs in the agricultural sector. There is substantial organic matter pollution in Büyük Çekmece and İznik Lakes located in the Marmara Basin. On the other hand, high chromium loaded water threatens the basin [23].

The purpose of this paper is to investigate the extent to which chromium(VI) ions are removed from aqueous solutions of activated carbon samples produced by physical and chemical activation methods using Tunçbilek lignite. The adsorption study parameters, $\mathrm{pH}$, temperature, and initial metal concentration, are investigated at various intervals. Langmuir and Freundlich adsorption isotherms are also used in the evaluation of the experimental data. The experimental tests are carried out according to a full $2^{4}$ factorial design with center points where the factors chosen were active carbon type (physical or chemical), temperature, $\mathrm{pH}$, and concentration. Similar research has been conducted for copper removal, as seen in the literature [24]. Regression analysis was applied to investigate the most effective factors among the examined parameters [24]. Regression analysis was also used in the study of cadmium ion adsorption [25]. A comparison with widely used empirical isotherms, such as Freundlich and Langmuir, is also given in order to confirm the validity and advantages of the obtained regression model. Additionally, experiments are conducted to indicate the capability of the active carbon samples obtained. For this purpose, the organic matter effect is investigated by adding sucrose to the adsorption medium.

\section{Materials and Experimental Method}

2.1. ANOVA and Regression Analysis. As discussed before, the experimental tests are carried out according to a full twolevel four-factor $\left(2^{4}\right)$ factorial design with center points, and the four factors (low and high level in parentheses) chosen were active carbon type (physical active carbon (PAC); chemical active carbon (CAC)), ppm ( $25 \mathrm{mg} / \mathrm{L} ; 1200 \mathrm{mg} / \mathrm{L})$, temperature $(298 \mathrm{~K} ; 323 \mathrm{~K})$, and $\mathrm{pH}(2 ; 6)$. Each test was replicated once. The above values are selected from the values currently used in the industry. The analysis of variance method (ANOVA) is used to examine whether the effect and the interaction between the examined factors were significant in relation to the experimental error [26-28].

The experimental design is used to analyze the effects of many process parameters. Its usage usually decreases the number of experiments, in addition to decreasing time and material resources. Furthermore, the experimental errors are minimized $[26,27]$. It is known that a potential concern in the use of two-level factorial designs is the linearity assumption in the factor effects [29]. If there are unreplicated factorial design points in the experiment, one may use replicated "center points" to create a curvature effect. Although exact linearity is not needed and the experimental design will be valid when there is approximate linearity, it is usually better to use center point runs in the design if the researcher is at all uncertain about the order of the model that should be utilized [29]. In the present study, it is known that the relationship may be nonlinear and that curvature may be present; therefore, center points were consequently added to the design.

2.2. Experimental Procedure. Chemically and physically activated carbon samples produced from Tunçbilek lignite are used in this study. The active carbon sample preparation method and the textural and chemical properties are given in [29]. Since there are two different types of activated carbon that may have differing absorbing capacities, it is concluded that active carbon type can be chosen as a factor in the experimental design.

The experimental conditions for the physical and chemical activation methods described are as follows:

(i) Physical activation process: $\mathrm{CO}_{2}$ is used as activating gas in the production of physical activated carbon. The raw material was subjected to a thermal decomposition process at $1073 \mathrm{~K}$ with a heating rate of $30 \mathrm{~K} / \mathrm{min}$ in a nitrogen gas environment. Then, $\mathrm{CO}_{2}$ gas was supplied to the environment at a rate of 
$1223 \mathrm{~K}$ at the same heating rate, and activation was carried out at this temperature for 3 hours.

(ii) Chemical activation process: The material to be activated with a zinc chloride solution prepared as $1 /$ 1 by mass ratio was mixed for 2 hours at a speed of $300 \mathrm{rpm}$. After stirring, the sample was incubated at $298 \mathrm{~K}$ for 18 hours and then filtered through filter paper to remove the solution. The sample containing a certain amount of zinc chloride was activated in an $\mathrm{N}_{2}$ gas atmosphere for 2 hours at a temperature of $1073 \mathrm{~K}$ with a heating rate of $30 \mathrm{~K} / \mathrm{min}$. After chemical activation, the recovered product was washed with $0.5 \mathrm{~N} \mathrm{HCl}$ solution to remove remaining zinc chloride. Subsequently, washing was continued with a large amount of hot distilled water to remove the $\mathrm{HCl}$ solution. The washed product was dried for 14 hours at $600 \mathrm{mmHg}$ under vacuum at $343 \mathrm{~K}$.

The results of short and elemental analysis of the initial raw materials and the active carbon samples produced from them are shown in Table 1 . When Table 1 is examined, it is seen that the amount of fixed carbon, which is essential for adsorption, increases with the physical activation process.

The batch adsorption experiments are performed in acidic medium ( $\mathrm{pH}: 2.0-6.0$ ), and the adsorption temperatures selected are 298, 308, and $323 \mathrm{~K}$. The initial chromium(VI) ion concentration is in the range of $25 \mathrm{mg} / \mathrm{L}$ to $1200 \mathrm{mg} / \mathrm{L}$.

2.3. Mathematical Modeling. The experiments are conducted as follows: the controllable factors and their levels are given in Table 2. In addition, experimental runs and responses are given in Table 3. After the initial analysis summarized in Figures 1 and 2, it has been concluded that the most effective control parameters are $B, C, D$, and the interactions between $B$ and $C(B C)$ together with $C$ and $D$ $(C D)$. This result actually indicated that active carbon type did not play a role as a factor in the current experimental conditions. In fact, when the results of the experiments are studied, it is clear that PAC and CAC activated carbon samples had similar surface functional groups [30]. Properties of activated carbon samples are analyzed, and it is observed that PAC and CAC samples were very similar to each other in terms of Fourier transform infrared spectroscopy (FTIR). Therefore, it is concluded that adsorption was not affected by the activated carbon type [30].

When active carbon samples are examined, it is noted that peaks are mostly collected in two ranges. These range $700-1300 \mathrm{~cm}^{-1}$ and $1300-1900 \mathrm{~cm}^{-1}$. Peaks in the range of $1000-1300 \mathrm{~cm}^{-1}$ can result from the ether and phenolic structures. Peaks in the range of $700-900 \mathrm{~cm}^{-1}$ in samples indicate aromatic C-H structures. It is clearly seen that PAC and CAC samples show great similarities in terms of surface functional groups. The peaks contained in the PAC sample between 2800 and $2980 \mathrm{~cm}^{-1}$ show that there are more aliphatic hydrogenated structures in the structure, and the peaks between 3000 and $3100 \mathrm{~cm}^{-1}$ contained in the CAC sample have more aromatic hydrogen structures in the structure (Figures 3 and 4).

Peaks in the range of $2700-3000 \mathrm{~cm}^{-1}$ in PAC-coded samples indicate the peaks of aliphatic $\mathrm{CH}, \mathrm{CH}_{2}$, and $\mathrm{CH}_{3}$. In the PAC-coded samples, it was found that the peaks in the range of $900-1300 \mathrm{~cm}^{-1}$ could contain $-\mathrm{C}-\mathrm{O}$ and $-\mathrm{OH}$ structures of alcohol, phenol, and carboxylic groups. Peaks in the range of $2700-3000 \mathrm{~cm}^{-1}$ in all CAC-coded samples indicate the peaks of aliphatic $\mathrm{CH}, \mathrm{CH}_{2}$, and $\mathrm{CH}_{3}$. The peaks of $2000 \pm 100 \mathrm{~cm}^{-1}$ in the PAC and CAC samples show the $\mathrm{C} \equiv \mathrm{O}$ structure.

After the above analysis, a linear regression correlation between $q_{\mathrm{e}}$ and the experimental parameters is developed using the Minitab 16 software [24]. The equations for both coded and uncoded units are given below:

$$
\begin{aligned}
q_{\mathrm{e}}= & +8.519+0.826 * B+7.868 * C-2.141 * D \\
& +0.779 * B C-2.033 * C D \text { (coded units) } \\
q_{\mathrm{e}}= & +0.018+0.001 * B-0.013 * C-0.011 * D \\
& +1.061 E^{-4} * B C-0.002 * C D \text { (uncoded units). }
\end{aligned}
$$

The results and predicted values from equations (1) and (2) are tabulated in Tables 3 and 4 . Table 4 provides the ANOVA results: these results indicate that the chosen parameters are indeed most effective and, additionally, that there is no curvature effect. In addition, $R^{2}$ is $99.14 \%$, which indicates that the relationship is almost linear and that we have obtained a good fit.

According to the linear regression results, the initial chromium concentration coefficient is the highest among all of the coefficients. However, it has been observed that the $\mathrm{pH}$ of the activated carbon is adversely affected by chromium adsorption. As seen from the adsorption temperature coefficient, the chromium adsorption has also increased considerably with increasing temperature. This linear regression analysis shows that the experimental results correspond to the analysis results.

\section{Results and Discussion}

3.1. Temperature Effect on Chromium(VI) Adsorption. The effect of the temperature on chromium(VI) adsorption is investigated at temperatures of 298,308 , and $323 \mathrm{~K}$. When the initial concentration of $1200 \mathrm{mg} / \mathrm{L}$ was examined, it was observed that the adsorption of chromium(VI) ions for both activated carbon samples increased with escalating adsorption temperature (Table 3), i.e., from 20.593 to $22.964 \mathrm{mg} / \mathrm{g}$ AC and from 16.780 to $22.062 \mathrm{mg} / \mathrm{g}$ AC for PAC and CAC, respectively. Under the experimental conditions, it is seen that the amount of emitted chromium(VI) ions increases as temperature rises. This effect can especially be observed over $400 \mathrm{ppm}$ concentration values. The adsorption differences observed between PAC and CAC samples at lower temperatures decrease at higher temperatures [30]. This can also be seen in the main effects plot in Figure 5. The adsorbed amount of chromium(VI) ions depends on the chemical interaction between carbon surface groups and adsorbed ions. The increase in the chemical 
TABLE 1: Results of short and elemental analysis of activated carbon samples.

\begin{tabular}{lccccccc}
\hline Sample & Volatile compound (\%) & Fixed carbon $^{(\mathrm{a})}(\%)$ & $\mathrm{Ash}^{(\mathrm{a})}(\%)$ & $\mathrm{C}^{(\mathrm{b})}(\%)$ & $\mathrm{H}^{(\mathrm{b})}(\%)$ & $N^{(\mathrm{b})}(\%)$ & $(\mathrm{S}+\mathrm{O})^{(\mathrm{b})}(\%)$ \\
\hline Raw material & 34.01 & 39.81 & 26.18 & 40.00 & 4.67 & 3.06 & 52.27 \\
PAC & 5.26 & 42.61 & 50.18 & 89.72 & 0.10 & 5.22 & 4.96 \\
CAC & 9.38 & 63.43 & 27.19 & 62.90 & 0.87 & 5.37 & 30.86 \\
\hline
\end{tabular}

${ }^{(\mathrm{a})}$ Dry; ${ }^{(\mathrm{b})}$ dry-ashless.

TABLE 2: Controllable factors and their levels.

\begin{tabular}{lcccc}
\hline Factor & Description & Low level & Center point & High level \\
\hline$A$ & Active carbon type & PAC & - & CAC \\
$B$ & Temperature (K) & 298 & 310.5 & 323 \\
$C$ & ppm & 25 & 612.5 & 1200 \\
$D$ & $\mathrm{pH}$ & 2 & 4 & 6 \\
\hline
\end{tabular}

TABLE 3: Experimental runs and their results and predicted values from the regression analysis.

\begin{tabular}{|c|c|c|c|c|c|c|}
\hline Run no. (actual) & Active carbon type (A) & Temperature (K) (B) & $\mathrm{ppm}(\mathrm{mg} / \mathrm{L})(\mathrm{C})$ & $\mathrm{pH}(\mathrm{D})$ & $q_{\mathrm{e}}(\mathrm{mg} / \mathrm{g} \mathrm{AC})$ & Predicted $q_{\mathrm{e}}(\mathrm{mg} / \mathrm{g} \mathrm{AC})$ \\
\hline $1(1)$ & PAC & 298.0 & 25.0 & 2 & 0.840 & 0.712 \\
\hline $2(3)$ & PAC & 323.0 & 25.0 & 2 & 0.884 & 0.805 \\
\hline $3(5)$ & PAC & 298.0 & 1200.0 & 2 & 20.593 & 18.957 \\
\hline $4(7)$ & PAC & 323.0 & 1200.0 & 2 & 22.964 & 22.167 \\
\hline $5(9)$ & PAC & 298.0 & 25.0 & 6 & 0.549 & 0.496 \\
\hline $6(11)$ & PAC & 323.0 & 25.0 & 6 & 0.732 & 0.589 \\
\hline $7(13)$ & PAC & 298.0 & 1200.0 & 6 & 10.917 & 10.608 \\
\hline $8(15)$ & PAC & 323.0 & 1200.0 & 6 & 12.771 & 13.818 \\
\hline $9(17)$ & PAC & 310.5 & 612.5 & 4 & 8.370 & 8.519 \\
\hline $10(2)$ & CAC & 298.0 & 25.0 & 2 & 0.724 & 0.712 \\
\hline $11(4)$ & CAC & 323.0 & 25.0 & 2 & 0.737 & 0.805 \\
\hline $12(6)$ & CAC & 298.0 & 1200.0 & 2 & 16.780 & 18.957 \\
\hline $13(8)$ & CAC & 323.0 & 1200.0 & 2 & 22.062 & 22.167 \\
\hline $14(10)$ & CAC & 298.0 & 25.0 & 6 & 0.454 & 0.496 \\
\hline 15 (12) & CAC & 323.0 & 25.0 & 6 & 0.588 & 0.589 \\
\hline $16(14)$ & CAC & 298.0 & 1200.0 & 6 & 10.992 & 10.608 \\
\hline 17 (16) & CAC & 323.0 & 1200.0 & 6 & 14.324 & 13.818 \\
\hline $18(18)$ & CAC & 310.5 & 612.5 & 4 & 8.060 & 8.519 \\
\hline
\end{tabular}

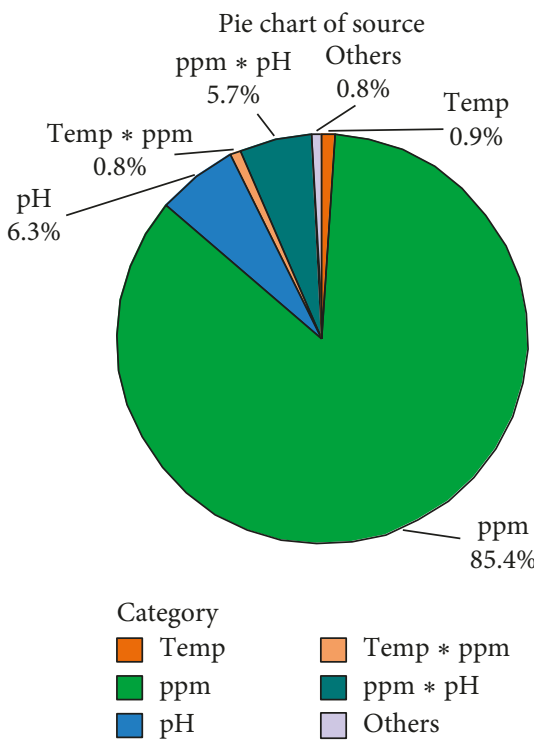

Figure 1: Pie chart of factors affecting $q_{\mathrm{e}}$.

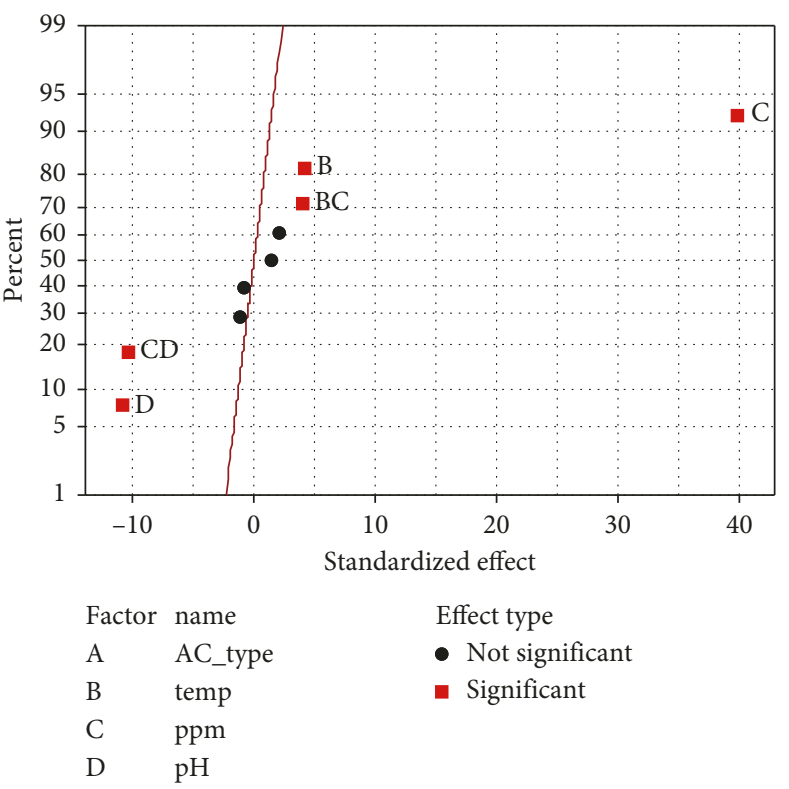

FIgURE 2: Normal plot of the standardized effects (response is $q_{\mathrm{e}}$, alpha $=0.05)$. 


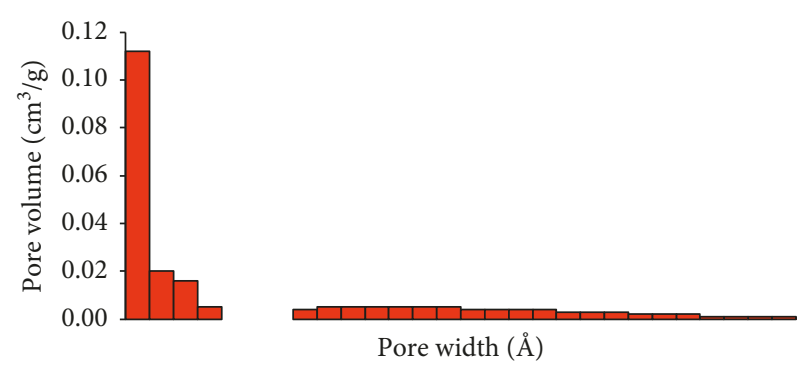

(a)

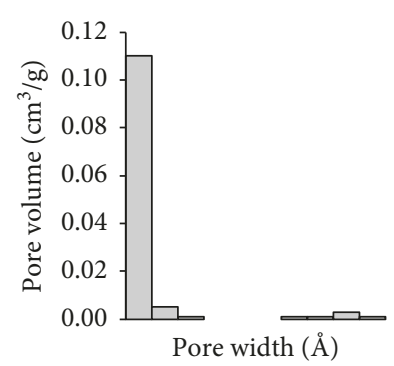

(b)

FIgURe 3: Pore volume distributions of active carbon samples according to the DFT (density functional theory) method. (a) Physically activated carbon (PAC). (b) Chemically activated carbon (CAC).

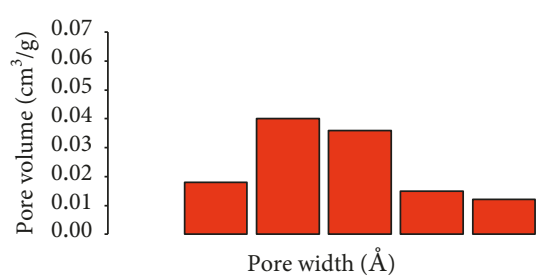

(a)

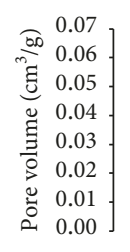

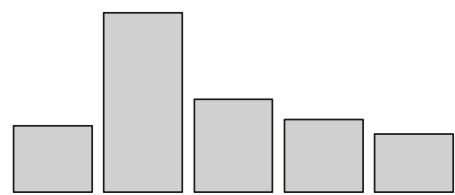

Pore width $(\AA)$

(b)

Figure 4: Pore volume distributions by applying Monte Carlo simulation to $\mathrm{CO}_{2}$ adsorption data of activated carbon samples. (a) Physically activated carbon (PAC). (b) Chemically activated carbon (CAC).

TABLE 4: Results of the regression analysis.

\begin{tabular}{|c|c|c|c|c|c|c|}
\hline \multicolumn{7}{|c|}{ Analysis of variance for $q_{\mathrm{e}}$ (coded units) } \\
\hline Source & $\mathrm{DF}$ & Seq SS & Adj SS & Adj MS & $\mathrm{F}$ & $P$ \\
\hline Main effects & 3 & 1074.84 & 1074.84 & 358.279 & 432.36 & 0 \\
\hline Temp & 1 & 10.91 & 10.91 & 10.915 & 13.17 & 0.003 \\
\hline Ppm & 1 & 990.57 & 990.57 & 990.569 & 1195.4 & 0 \\
\hline $\mathrm{pH}$ & 1 & 73.35 & 73.35 & 73.353 & 88.52 & 0 \\
\hline 2-way interactions & 2 & 75.86 & 75.86 & 37.929 & 45.77 & 0 \\
\hline Temp $*$ ppm & 1 & 9.71 & 9.71 & 9.711 & 11.72 & 0.005 \\
\hline $\mathrm{ppm} * \mathrm{pH}$ & 1 & 66.15 & 66.15 & 66.146 & 79.82 & 0 \\
\hline Residual error & 12 & 9.94 & 9.94 & 0.829 & & \\
\hline Curvature & 1 & 0.21 & 0.21 & 0.208 & 0.23 & 0.637 \\
\hline Lack of fit & 2 & 0.77 & 0.77 & 0.385 & 0.39 & 0.69 \\
\hline Pure error & 9 & 8.97 & 8.97 & 0.996 & & \\
\hline Total & 17 & 1160.64 & & & & \\
\hline \multicolumn{7}{|c|}{ Estimated effects and coefficients for $q_{\mathrm{e}}$ (coded units) } \\
\hline Term & Effect & Coef & SE coef & $\mathrm{T}$ & $\mathrm{P}$ & \\
\hline Constant & & 8.519 & 0.2146 & 39.7 & 0 & \\
\hline Temp & 1.652 & 0.826 & 0.2276 & 3.63 & 0.003 & \\
\hline ppm & 15.737 & 7.868 & 0.2276 & 34.57 & 0 & \\
\hline $\mathrm{pH}$ & -4.282 & -2.141 & 0.2276 & -9.41 & 0 & \\
\hline Temp $*$ ppm & 1.558 & 0.779 & 0.2276 & 3.42 & 0.005 & \\
\hline $\mathrm{ppm} * \mathrm{pH}$ & -4.067 & -2.033 & 0.2276 & -8.93 & 0 & \\
\hline S & 0.910304 & PRESS & 24.5778 & & & \\
\hline $\mathrm{R}-\mathrm{Sq}$ & $99.14 \%$ & $\mathrm{R}-\mathrm{Sq}$ (pred) & $97.88 \%$ & R-Sq(adj) & $98.79 \%$ & \\
\hline
\end{tabular}

interaction between the sorbate ions and the surface functions of the activated carbons also increases the intraparticle diffusion of the sorbate ions via changing the amount of adsorption or the diffusion rate, which are dependent on the porosity due to the effect of temperature, as diffusion is an endothermic process [31]. The increase in adsorption capacity due to temperature may arise either from the behavioral properties of surface groups corresponding with temperature or from the effect of newly formed active sites at the surface due to the interaction of the diffusion, which occurs between activated carbon and adsorbed ions at high temperatures [30]. 


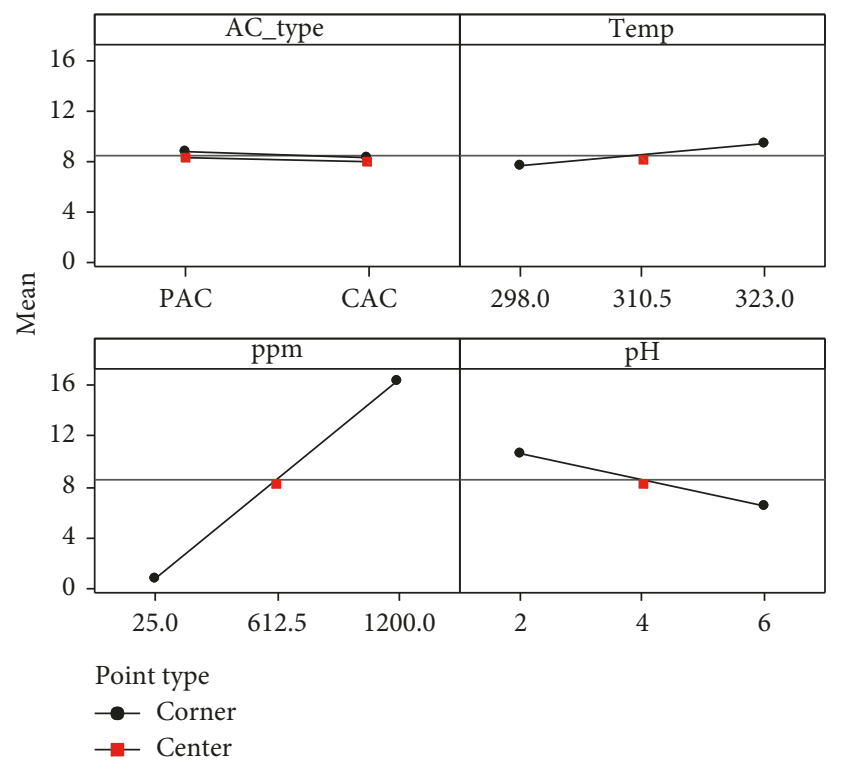

FIGURE 5: Main effects plot for $q_{\mathrm{e}}$ (Data means).

3.2. Initial Concentration Effect on Chromium(VI) Adsorption. The effect of the initial concentration on chromium(VI) adsorption is investigated from $25 \mathrm{mg} / \mathrm{L}$ to $1200 \mathrm{mg} / \mathrm{L}$. When the results of the experiment at $298 \mathrm{~K}$ were examined, the adsorbed amounts on PAC and CAC increased to 20.593 and $16.780 \mathrm{mg} / \mathrm{g} \mathrm{AC}$, respectively, from 0.840 to $0.724 \mathrm{mg} / \mathrm{g}$ AC with an increase in the initial chromium concentration from $25 \mathrm{mg} / \mathrm{L}$ to $1200 \mathrm{mg} / \mathrm{L}$ (Table 3). As seen from these results, the adsorption of metal ions is enhanced by increasing the initial ion concentration (Figure 5). The difference between the amount of adsorbed chromium(VI) ions on the activated carbon samples is due to the surface area and the total pore volume. The number of adsorbed ions detected on the activated carbon samples increased from that predicted by the initial concentration; this result arises because of the driving force of the initial metal concentration and the higher $C_{0}$ values, which, together, increased the rate of adsorption [30].

3.3. pHEffect on Chromium(VI) Adsorption. The effect of $\mathrm{pH}$ on chromium(VI) adsorption is investigated from $\mathrm{pH} 2$ to 6 at different adsorption temperature and initial concentrations. Upon changing the $\mathrm{pH}$ values of the solutions from 25 to $1200 \mathrm{mg} / \mathrm{L}$ at $298 \mathrm{~K}$, the amount of chromium(VI) adsorbed on PAC and CAC decreased from 0.840 to $0.724 \mathrm{mg} / \mathrm{g}$ AC to 0.549 and $0.454 \mathrm{mg} / \mathrm{g} \mathrm{AC}$, respectively (Table 3). The reason for this reduction in adsorption capacity is thought to be that the adsorption sites occupy the anionic species, such as $\mathrm{HCrO}_{4}^{-}, \mathrm{CrO}_{4}^{-2}$, and $\mathrm{Cr}_{2} \mathrm{O}_{7}^{-2}$, and delay the progression of these ions towards the sorbent surface [30]. It is clear from these results that the removal of chromium(VI) ions decreases upon increasing the $\mathrm{pH}$ of the solution [32]. This can also be observed in Figure 5.

3.4. Adsorption Isotherm. Langmuir and Freundlich adsorption isotherms are used to analyze the adsorption data obtained. The Freundlich equation has the following form:

$$
\begin{aligned}
q_{\mathrm{e}} & =K_{\mathrm{F}} C_{\mathrm{e}}^{1 / n} \text { (nonlinear form), } \\
\log q_{\mathrm{e}} & =\log K_{\mathrm{F}}+\frac{1}{n} \log C_{\mathrm{e}} \text { (linear form), }
\end{aligned}
$$

where $q_{\mathrm{e}}$ is the amount of solute adsorbed per unit weight of adsorbent in $\mathrm{mg} / \mathrm{g} \mathrm{AC}, C_{\mathrm{e}}$ is the equilibrium concentration of solute in the bulk solution in $\mathrm{mg} / \mathrm{L}, K_{\mathrm{F}}$ is a constant indicative of the relative adsorption capacity of the adsorbent in $\mathrm{mg} / \mathrm{g} \mathrm{AC}$, and $1 / n$ is a constant indicative of the intensity of the adsorption $[33,34]$.

The $\log \left(C_{\mathrm{e}}\right)$ graph plotted against $\log \left(q_{\mathrm{e}}\right)$ shows $K_{\mathrm{F}}$ and $n$ values, which provide information on adsorption bond strength and bond distribution [32, 35].

It is known that the larger the values of $K_{\mathrm{F}}$ and $1 / n$ are, the greater the adsorption capacity is $[25,31]$. Values of $n$ between 1 and 3 are usually favorable for chromium(VI) adsorption [36]. According to the $n$ values, the type of adsorption is physical [37].

The Langmuir equation, on the other hand, is given as below:

$$
\frac{C_{\mathrm{e}}}{q_{\mathrm{e}}}=\left(\frac{1}{Q_{0} b}\right)+\left(\frac{1}{Q_{0}}\right) C_{\mathrm{e}},
$$

where $Q_{0}$ and $b$ are the Langmuir constants determined from the slope and intercept of the plot, which is indicative of maximum adsorption capacity in $\mathrm{mg} / \mathrm{g}$ of adsorbent and energy of adsorption, respectively [38, 39].

The graph of $C_{\mathrm{e}}$ versus $C_{\mathrm{e}} / q_{\mathrm{e}}$ provides the values of $Q_{0}$ and $b$ using the slope and the intercept point. The $b$ value indicates the adsorption energy, which is reflected by a rapid increase in adsorption at low concentrations of the adsorbate.

The results obtained with the application of Freundlich and Langmuir isotherms at pH 2.0 are given in Figures 6 and 7. Correlation coefficients and related Freundlich and Langmuir parameters have been reported before [9, 25, 32].

It can be seen from Figures 6 and 7 and Table 5 that the Freundlich model fit the results well. In fact, this result was an expected one because many researchers indicate that nonlinear isotherm models are better than linear models for adsorption characteristics [40].

On the other hand, the linear regression model developed in this paper, although linear, can predict the adsorption characteristics acceptably within the experimental conditions. To validate this, new experiments are conducted (Table 4) at the same temperatures, although with different ppm values, and the chi-square error is calculated according to the equation below:

$$
\text { chi }- \text { square }=\chi^{2}=\sum_{1}^{N} \frac{\left(q_{\mathrm{e}}-q_{\mathrm{em}}\right)^{2}}{q_{\mathrm{e}}} .
$$

In this equation, $q_{\mathrm{em}}$ refers to the values calculated by the isotherm models. The experimental and calculated values and related Freundlich and Langmuir parameters and their fit performances are given in Table 5.

\section{Application}

In this section, the chromium adsorption behavior of activated carbon in the presence of organic (such as sucrose) 


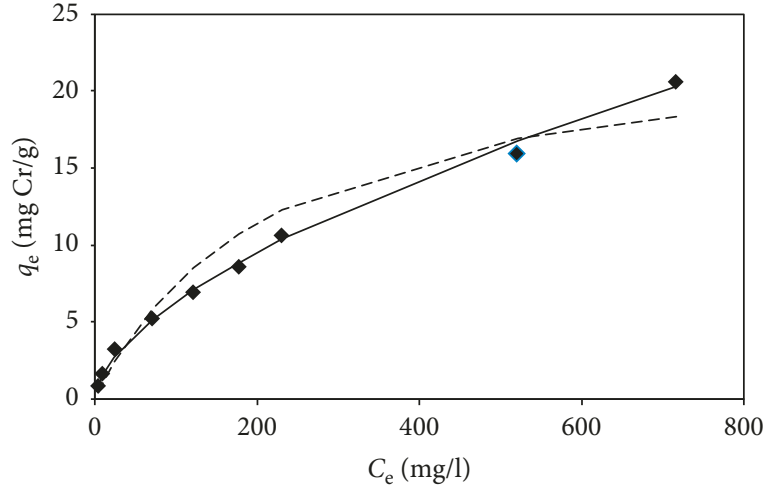

- Experimental

— Freundlich

--- Langmuir

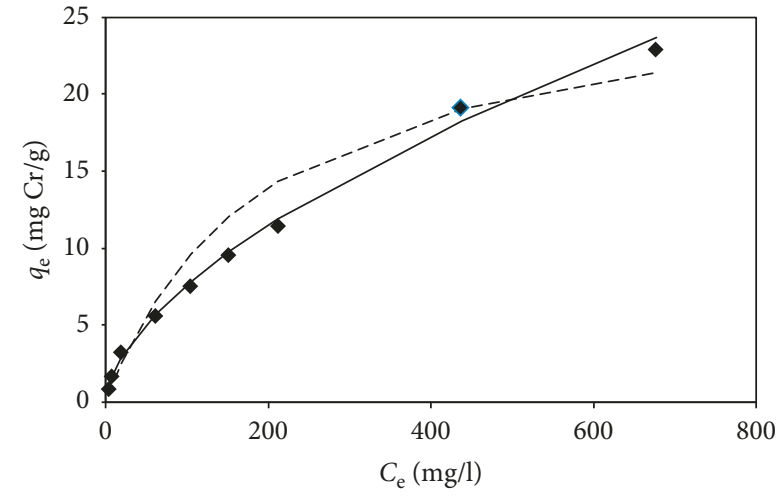

- Experimental

- Freundlich

--- Langmuir

(a)

(b)

Figure 6: Adsorption of chromium(VI) on PAC at $298 \mathrm{~K}$ (a) and $323 \mathrm{~K}$ (b). Solid line: fitting to the Freundlich isotherm; dashed line: fitting to the Langmuir isotherm.

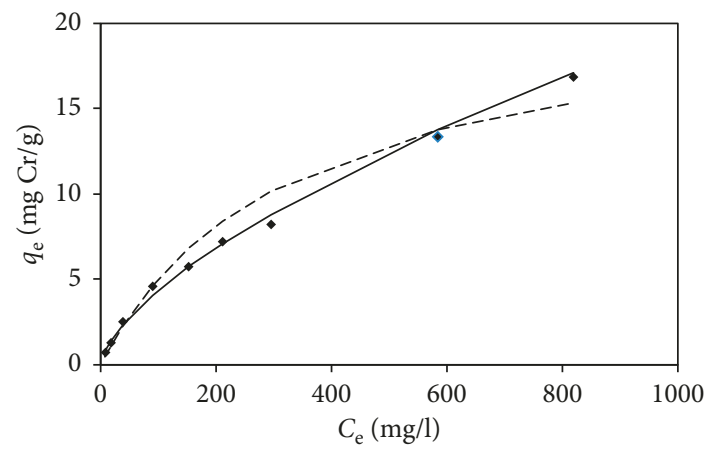

- Experimental

- Freundlich

--- Langmuir

(a)

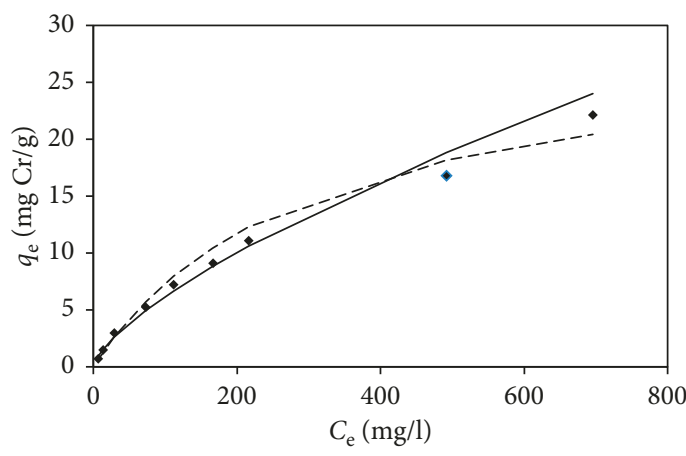

- Experimenta
- Freundlich
--- Langmuir

(b)

FIgUre 7: Adsorption of chromium(VI) on CAC at $298 \mathrm{~K}$ (a) and $323 \mathrm{~K}$ (b). Solid line: fitting to the Freundlich isotherm; dashed line: fitting to the Langmuir isotherm.

and inorganic substances is investigated. Because of the very different nature of the organic substances that can be used in industrial production environments and because of the practical limitations of their respective studies, the organic matter effect is usually investigated by adding sucrose to the adsorption medium. Adsorption experiments were carried out in this study with the addition of a solution of sucrose containing heavy metals and other inorganic ions, so that the concentration of organic matter in the medium would be $50 \mathrm{mg} / \mathrm{l}$, in order to be able to observe the effect of the organic structures on the heavy metal ions under study. Inorganic structures and concentrations in this solution are $\mathrm{Ca}^{+2}$ $(40 \mathrm{mg} / \mathrm{l}), \mathrm{Mg}^{+2}(15 \mathrm{mg} / \mathrm{l}), \mathrm{Na}^{+}(37 \mathrm{mg} / \mathrm{l}), \mathrm{Cl}^{-}(58 \mathrm{mg} / \mathrm{l})$, $\mathrm{HCO}_{3}{ }^{-}(12 \mathrm{mg} / \mathrm{l})$, and $\mathrm{SO}_{4}{ }^{-2}(60 \mathrm{mg} / \mathrm{l})$. The results are shown comparatively in Figure 8. As can be clearly seen, the presence of organic matter in the medium significantly reduces the holding capacity of the relevant heavy metal ion of the active carbon. This may be because organic constituents with large molecular structures block the pores in the adsorption result, adsorbing the organic materials more strongly on active surface groups which are sensitive to heavy metal ions and not allowing the adsorption of heavy metal ions. The magnitudes of these reductions in the presence of sucrose and additional inorganic material for $\mathrm{Cr}(\mathrm{VI})$ ion adsorption are $37-46 \%$ and $54-61 \%$ for the PAC sample and between $38-$ $44 \%$ and $55-59 \%$ for the CAC sample, respectively.

It is possible that organic matter affects adsorption positively, depending on the functional groups on the surface where it is adsorbed. For this reason, the adsorption of heavy metal ions on activated carbon should be investigated in detail in the presence of various organic substances.

\section{Conclusion}

In this study, active carbons with different textural and chemical properties were produced, and the chromium(VI) 
TABLE 5: Freundlich and Langmuir isotherm constants, chromium(VI) adsorption values, and model performances at different temperatures $(\mathrm{pH}=2)$.

\begin{tabular}{|c|c|c|c|c|c|c|c|c|}
\hline \multirow{2}{*}{ ppm } & \multicolumn{2}{|c|}{ PAC, $298 \mathrm{~K}$} & \multicolumn{2}{|c|}{ PAC, $323 \mathrm{~K}$} & \multicolumn{2}{|c|}{ CAC, $298 \mathrm{~K}$} & \multicolumn{2}{|c|}{ CAC, $323 \mathrm{~K}$} \\
\hline & $C_{\mathrm{e}}(\mathrm{mg} / \mathrm{L})$ & $q_{\mathrm{e}}(\mathrm{mg} / \mathrm{g} \mathrm{AC})$ & $C_{\mathrm{e}}(\mathrm{mg} / \mathrm{L})$ & $q_{\mathrm{e}}(\mathrm{mg} / \mathrm{g} \mathrm{AC})$ & $C_{\mathrm{e}}(\mathrm{mg} / \mathrm{L})$ & $q_{\mathrm{e}}(\mathrm{mg} / \mathrm{g} \mathrm{AC})$ & $C_{\mathrm{e}}(\mathrm{mg} / \mathrm{L})$ & $q_{\mathrm{e}}(\mathrm{mg} / \mathrm{g} \mathrm{AC})$ \\
\hline 25 & 3.775 & 0.840 & 3.050 & 0.880 & 7.100 & 0.720 & 6.142 & 0.740 \\
\hline 50 & 9.849 & 1.580 & 7.551 & 1.680 & 16.349 & 1.310 & 12.610 & 1.440 \\
\hline 100 & 23.796 & 3.160 & 19.028 & 3.310 & 37.728 & 2.550 & 28.565 & 2.950 \\
\hline 200 & 70.785 & 5.180 & 61.090 & 5.620 & 89.769 & 4.520 & 72.402 & 5.230 \\
\hline 300 & 121.013 & 6.950 & 104.855 & 7.570 & 152.051 & 5.710 & 111.059 & 7.200 \\
\hline 400 & 177.218 & 8.560 & 151.290 & 9.600 & 210.195 & 7.210 & 165.639 & 9.100 \\
\hline 500 & 230.679 & 10.590 & 211.710 & 11.480 & 294.145 & 8.180 & 216.393 & 11.090 \\
\hline 900 & 521.468 & 15.880 & 437.564 & 19.170 & 582.513 & 13.320 & 491.390 & 16.770 \\
\hline 1200 & 716.433 & 20.590 & 676.762 & 22.960 & 817.680 & 16.780 & 695.273 & 22.060 \\
\hline \multicolumn{9}{|c|}{ Freundlich isotherm } \\
\hline$K_{\mathrm{F}}$ & \multicolumn{2}{|c|}{0.415} & \multicolumn{2}{|c|}{0.498} & \multicolumn{2}{|r|}{0.219} & \multicolumn{2}{|c|}{0.244} \\
\hline$n$ & \multicolumn{2}{|r|}{1.690} & \multicolumn{2}{|c|}{1.688} & \multicolumn{2}{|r|}{1.540} & \multicolumn{2}{|c|}{1.427} \\
\hline$R^{2}$ & \multicolumn{2}{|r|}{0.996} & \multicolumn{2}{|c|}{0.996} & \multicolumn{2}{|r|}{0.996} & \multicolumn{2}{|c|}{0.992} \\
\hline$\chi^{2}$ & \multicolumn{2}{|r|}{0.150} & \multicolumn{2}{|c|}{0.160} & \multicolumn{2}{|r|}{0.140} & \multicolumn{2}{|c|}{0.590} \\
\hline \multicolumn{9}{|c|}{ Langmuir isotherm } \\
\hline$Q_{0}$ & \multicolumn{2}{|c|}{23.923} & \multicolumn{2}{|c|}{27.624} & \multicolumn{2}{|c|}{21.322} & \multicolumn{2}{|c|}{28.986} \\
\hline$b$ & \multicolumn{2}{|c|}{0.005} & \multicolumn{2}{|c|}{0.005} & \multicolumn{2}{|c|}{0.003} & \multicolumn{2}{|c|}{0.003} \\
\hline$R^{2}$ & \multicolumn{2}{|c|}{0.895} & \multicolumn{2}{|c|}{0.893} & & 0.898 & & 0.942 \\
\hline$\chi^{2}$ & & 2.220 & & 880 & & 1.250 & & 0.810 \\
\hline$D O E$ & & & & & & & & \\
\hline$R^{2}$ & & 0.988 & & 988 & & 0.988 & & 0.988 \\
\hline$\chi^{2}$ & & 3.210 & & 500 & & 0.990 & & 1.280 \\
\hline
\end{tabular}

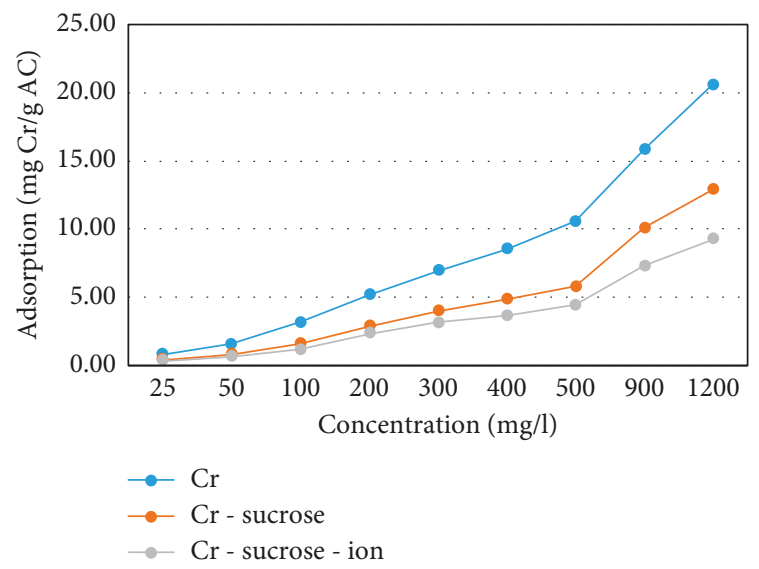

(a)

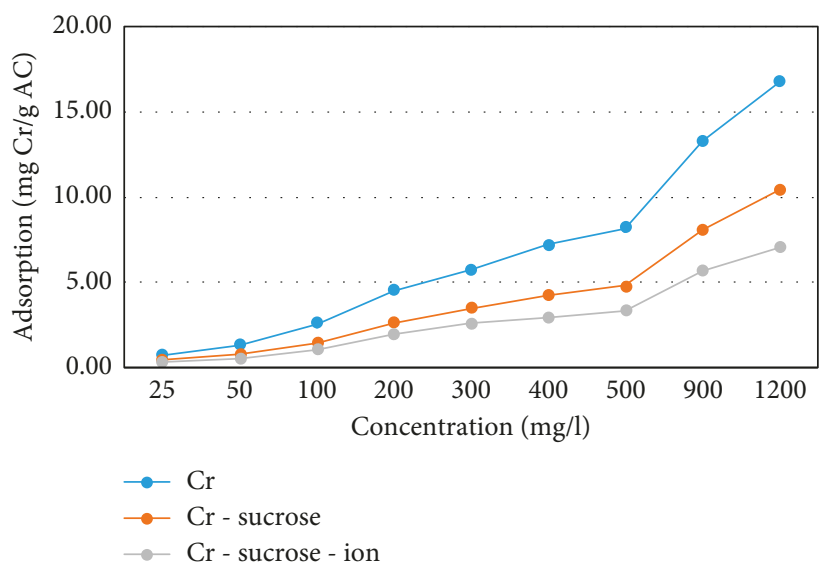

(b)

Figure 8: Adsorption behavior of heavy metal ions in the presence of sucrose and various inorganic ions. (a) PAC, pH: 2, T: 298 K (b) CAC, pH: 2, T: $298 \mathrm{~K}$.

concentration, adsorption temperature, and $\mathrm{pH}$ effects of these activated carbons were investigated. The results indicated that physical activated carbon obtained from Tunçbilek lignite is more effective than chemical activated carbon for the removal of chromium(VI) from aqueous solutions. The mineral matter structure contained in the activated carbon samples produced may affect the uptake of chromium ions. It is clear that increasing the initial chromium(VI) concentration from 25 to $1200 \mathrm{mg} / \mathrm{L}$ also increases the adsorption capacity. The decreasing effect of the solution $\mathrm{pH}$ is apparent. The adsorption capacity at $323 \mathrm{~K}$ represents the maximum level. Increased surface areas and total pore volumes of the samples were also found to increase chromium uptake. According to the results obtained from the statistical design technique, chromium adsorption is affected differently by parameters of temperature, $\mathrm{pH}$, and initial chromium concentration. It can be seen that the predicted values from the regression model are in good agreement with the actual values from the experiments. Therefore, the accuracy of the model in predicting the $q_{\mathrm{e}}$ values is established. It was also found from the adsorption isotherms that the chromium(VI) adsorption isotherms of activated carbons can be described by the Freundlich model, but the regression model provides a simpler and more 
efficient equation which is valid for all of the experimental condition values within the design limits. As previously (see Section 2.2) discussed, the active carbons that are produced from the Tunçbilek lignite have low thermal capability and low internal area when in the raw state. Although this is the case, chemical and physical processes have transformed this lignite into a very useful industrial product. This product is currently utilized for industrial applications, and research is still ongoing for further improvements.

\section{Data Availability}

The data used to support the findings of this study are available from the corresponding author upon request.

\section{Conflicts of Interest}

The authors declare that they have no conflicts of interest.

\section{References}

[1] C. Lao, Z. Zeledón, X. Gamisans, and M. Solé, "Sorption of $\mathrm{Cd}(\mathrm{II})$ and $\mathrm{Pb}$ (II) from aqueous solutions by a low-rank coal (leonardite)," Separation and Purification Technology, vol. 45, no. 2, pp. 79-85, 2005.

[2] M. Uçurum, "A study of removal of $\mathrm{Pb}$ heavy metal ions from aqueous solution using lignite and a new cheap adsorbent (lignite washing plant tailings)," Fuel, vol. 88, no. 8, pp. 1460-1465, 2009.

[3] A. Tanweer, D. Mohammad, R. Mohammad et al., "The use of date palm as a potential adsorbent for wastewater treatment: a review," Environmental Science and Pollution Research, vol. 19, no. 5, pp. 1464-1484, 2012.

[4] AA. Zeid, N. Mu, and A. Rahmat, "Kinetic, equilibrium isotherm and thermodynamic studies of $\mathrm{Cr}(\mathrm{VI})$ adsorption onto low-cost adsorbent developed from peanut shell activated with phosphoric acid," Environmental Science and Pollution Research, vol. 20, no. 5, pp. 3351-3365, 2013.

[5] A. Tytlak, P. Oleszczuk, and R. Dobrowolski, "Sorption and desorption of $\mathrm{Cr}(\mathrm{VI})$ ions from water by biochars in different environmental conditions," Environmental Science and Pollution Research, vol. 22, no. 8, pp. 5985-5994, 2015.

[6] R. W. Rousseau, Handbook of Separation Process Technology, Wiley, New York, NY, USA, 1987.

[7] M. O. Corapcioglu and C. P. Huang, "The surface acidity and characterization of some commercial activated carbons," Carbon, vol. 25, no. 4, pp. 569-578, 1987.

[8] E. Iakovleva and M. Sillanpää, "The use of low-cost adsorbents for wastewater purification in mining industries," Environmental Science and Pollution Research, vol. 20, no. 11, pp. 7878-7899, 2013.

[9] D. C. Sharma and C. F. Forster, "The treatment of chromium wastewaters using the sorptive potential of leaf mould," Bioresource Technology, vol. 49, no. 1, pp. 31-40, 1994.

[10] D. C. Sharma and C. F. Forster, "Column studies into the adsorption of chromium(VI) using sphagnum moss peat," Bioresource Technology, vol. 52, no. 3, pp. 261-267, 1995.

[11] C. Raji and T. S. Anirudhan, "Chromium(VI) adsorption by sawdust carbon: kinetics and equilibrium," Indian Journal of Chemical Technology, vol. 4, pp. 228-236, 1997.

[12] K. Selvi, S. Pattabhi, and K. Kadirvelu, "Removal of Cr(VI) from aqueous solution by adsorption onto activated carbon," Bioresource Technology, vol. 80, no. 1, pp. 87-89, 2001.
[13] S. Park and W. Y. Jung, "Removal of chromium by activated carbon fibers plated with copper metal," Carbon-Science, vol. 2, pp. 15-21, 2001.

[14] V. K. Gupta, A. K. Shrivastava, and N. Jain, "Biosorption of chromium(VI) from aqueous solutions by green algae spirogyra species," Water Research, vol. 35, no. 17, pp. 40794085, 2001.

[15] F. Gode and E. Pehlivan, "Adsorption of $\mathrm{Cr}$ (III) ions by Turkish brown coals," Fuel Processing Technology, vol. 86, no. 8, pp. 875-884, 2005.

[16] S. Karabulut, A. Karabakan, A. Denizli, and Y. Yürüm, "Batch removal of copper(II) and zinc(II) from aqueous solutions with low-rank Turkish coals," Separation and Purification Technology, vol. 18, no. 3, pp. 177-184, 2000.

[17] K. Murakami, T. Yamada, K. Fuda, T. Matsunaga, and Y. Nishiyama, "The cation exchange properties of the heattreated Australian brown coal in the water-organic compounds mixed solutions," Fuel, vol. 76, no. 12, pp. 1085-1090, 1997.

[18] C. A. Burns, P. J. Cass, I. H. Harding, and R. J. Crawford, "Adsorption of aqueous heavy metals onto carbonaceous substrates," Colloids and Surfaces A: Physicochemical and Engineering Aspects, vol. 155, no. 1, pp. 63-68, 1999.

[19] Çr Arpa, E. Başyilmaz, S. Bektaş, Ö. Genç, and Y. Yürüm, "Cation exchange properties of low rank Turkish coals: removal of $\mathrm{Hg}, \mathrm{Cd}$ and $\mathrm{Pb}$ from waste water," Fuel Processing Technology, vol. 68, no. 2, pp. 111-120, 2000.

[20] N. Karatepe, "Adsorption of a non-ionic dispersant on lignite particle surfaces," Energy Conversion and Management, vol. 44, no. 8, pp. 1275-1284, 2003.

[21] J. Hanzlík, J. Jehlicka, O. O. Sebek, Z. Weishauptová, and V. V. Machovic, "Multi-component adsorption of Ag(I), $\mathrm{Cd}(\mathrm{II})$ and $\mathrm{Cu}(\mathrm{II})$ by natural carbonaceous materials," Water Research, vol. 38, pp. 2178-2184, 2004.

[22] E. Pehlivan and G. Arslan, "Removal of metal ions using lignite in aqueous solution-low cost biosorbents," Fuel Processing Technology, vol. 88, no. 1, pp. 99-106, 2007.

[23] M. Akın and G. Akın, "Importance of water, water potential in Turkey, water basins and water pollution," Ankara University Journal of Languages and History-Geography-DTCF Journal, vol. 47, pp. 105-118, 2007.

[24] BC. Gencosman, AY. Orbak, and İ. Orbak, "Factor Analysis and response surface optimization for copper removal from aqueous solutions," in Proceedings of the International Conference on Industrial Engineering and Operations Management (IEOM 2012), pp. 1286-1291, Rabat, Morocco, April 2012.

[25] M. Fawzy, M. Nasr, H. Nagy, and S. Helmi, "Artificial intelligence and regression analysis for $\mathrm{Cd}(\mathrm{II})$ ion biosorption from aqueous solution by Gossypium barbadense waste," Environmental Science and Pollution Research, vol. 25, no. 6, pp. 5875-5888, 2018.

[26] G. EB. Box, WG. Hunter, and J. S. Hunter, Statistics for Experimenters, Wiley, New York, NY, USA, 1978.

[27] D. C. Montgomery, Design and Analysis of Experiments, Wiley, New York, NY, USA, 7th edition, 2008.

[28] F. Ferella, G. Mazziotti Di Celso, I. De Michelis, V. Stanisci, and F. Vegliò, "Optimization of the transesterification reaction in biodiesel production," Fuel, vol. 89, no. 1, pp. 36-42, 2010.

[29] N. Karatepe, İ. Orbak, R. Yavuz, and A. Ö vuzeper, "Sulfur dioxide adsorption by activated carbons having different textural and chemical properties," Fuel, vol. 87, no. 15-16, pp. 3207-3215, 2008.

[30] I. Orbak, Removal of environmental pollutants by using activated carbon, Ph.D. thesis, Istanbul Technical University, Istanbul, Turkey, 2009. 
[31] Y. Guo, J. Qi, S. Yang, K. Yu, Z. Wang, and H. Xu, “Adsorption of $\mathrm{Cr}(\mathrm{VI})$ on micro- and mesoporous rice huskbased active carbon," Materials Chemistry and Physics, vol. 78, no. 1, pp. 132-137, 2002.

[32] V. K. Gupta, D. Pathania, S. Agarwal, and S. Sharma, "Removal of $\mathrm{Cr}(\mathrm{VI})$ onto Ficus carica biosorbent from water," Environmental Science and Pollution Research, vol. 20, no. 4, pp. 2632-2644, 2013.

[33] E. I. Unuabonah and K. O. Adebowale, "Optimization of kinetic data for two-stage batch adsorption of $\mathrm{Pb}$ (II) ions onto tripolyphosphate-modified kaolinite clay," Journal of Chemical Technology \& Biotechnology, vol. 84, no. 11, pp. 1726$1735,2009$.

[34] S. Nag, A. Mondal, N. Bar, and S. K. Das, "Biosorption of chromium(VI) from aqueous solutions and ANN modelling," Environmental Science and Pollution Research, vol. 24, no. 23, pp. 18817-18835, 2017.

[35] L. Khezami and R. Capart, "Removal of chromium(VI) from aqueous solution by activated carbons: kinetic and equilibrium studies," Journal of Hazardous Materials, vol. 123, no. 1-3, pp. 223-231, 2005.

[36] S. Babel and T. A. Kurniawan, "Cr(VI) removal from synthetic wastewater using coconut shell charcoal and commercial activated carbon modified with oxidizing agents and/or chitosan," Chemosphere, vol. 54, no. 7, pp. 951-967, 2004.

[37] A. M. Awwad and A. M. Farhan, "Equilibrium, kinetic and thermodynamics of biosorption of lead (II) copper (II) and cadmium (II) ions from aqueous solutions onto olive leaves powder," American Journal of Chemistry, vol. 2, no. 4, pp. 238-244, 2012.

[38] R. Yavuz, İ. Orbak, and N. Karatepe, "Factors affecting the adsorption of chromium(VI) on activated carbon," Journal of Environmental Science and Health, Part A, vol. 41, no. 9, pp. 1967-1980, 2007.

[39] A. Şencan, M. Karaboyacı, and M. Kılıç, "Determination of lead(II) sorption capacity of hazelnut shell and activated carbon obtained from hazelnut shell activated with $\mathrm{ZnCl}_{2}$," Environmental Science and Pollution Research, vol. 22, no. 5, pp. 3238-3248, 2015.

[40] B. Subramanyam and A. Das, "Linearized and non-linearized isotherm models comparative study on adsorption of aqueous phenol solution in soil," International Journal of Environmental Science \& Technology, vol. 6, no. 4, pp. 633-640, 2009. 

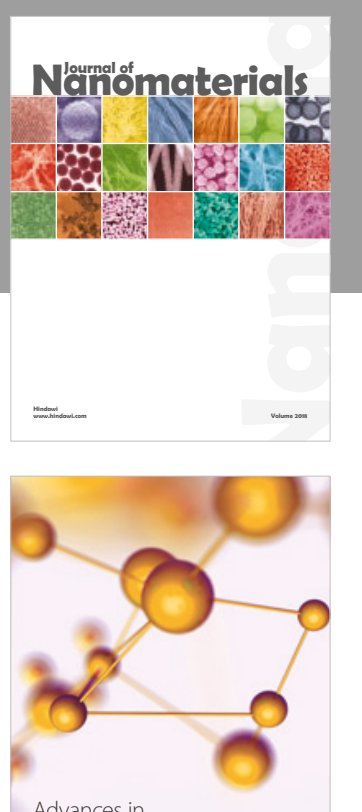

Physical Chemistry
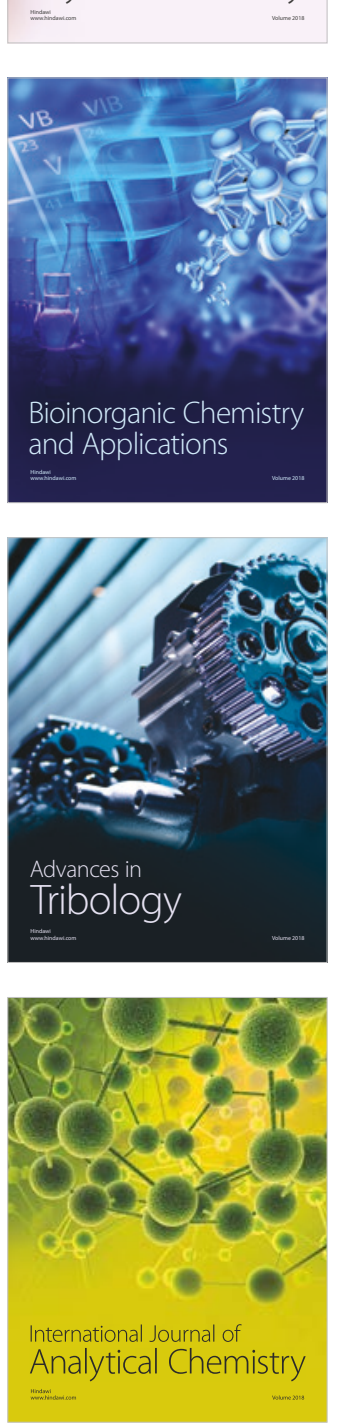

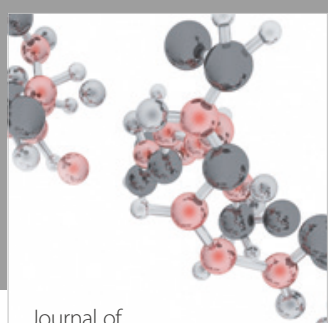

Analytical Methods

in Chemistry

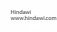

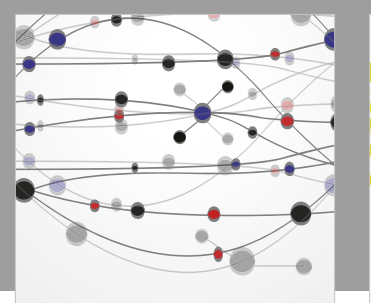

The Scientific World Journal

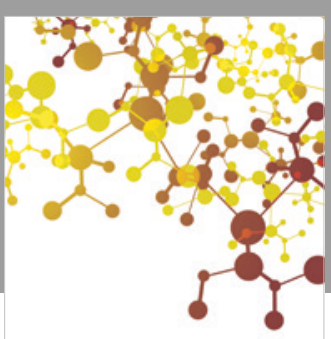

Journal of

Applied Chemistry
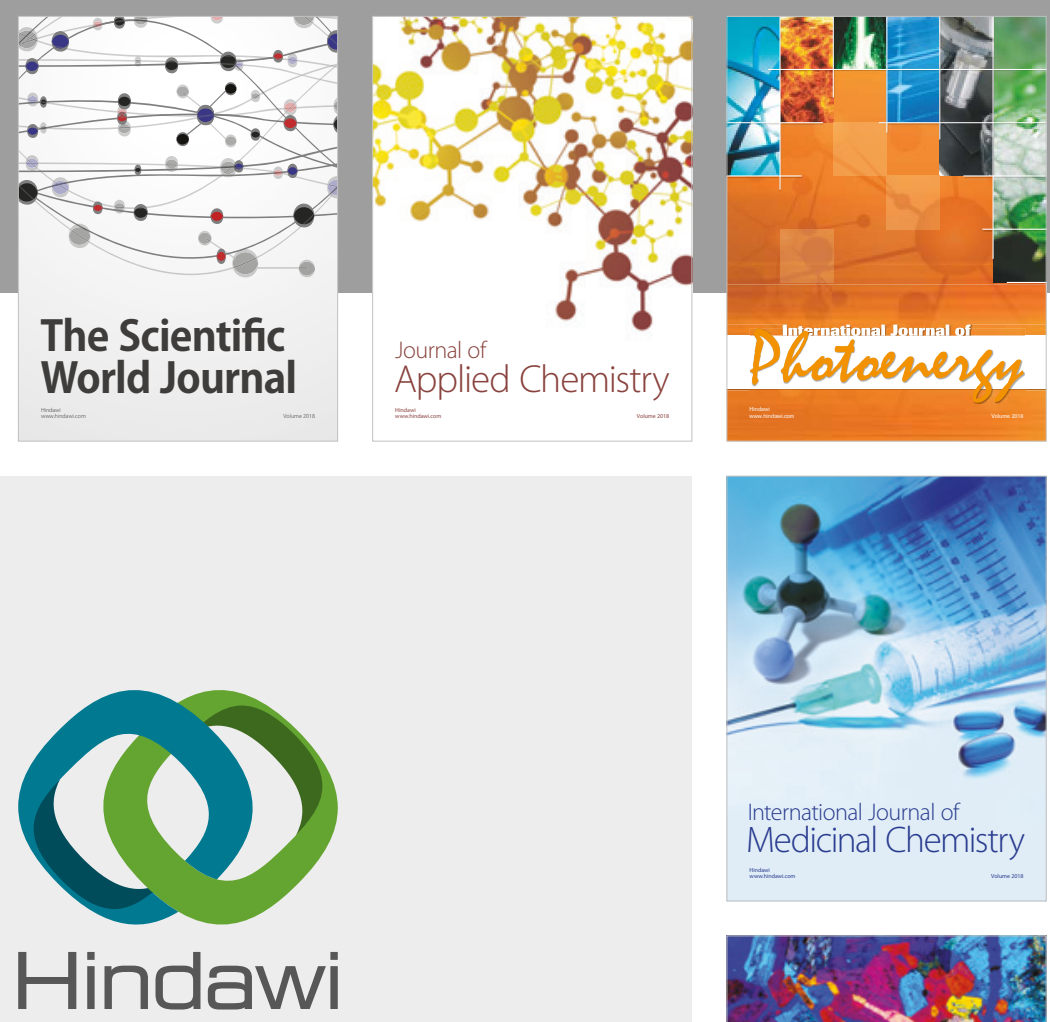

Submit your manuscripts at

www.hindawi.com
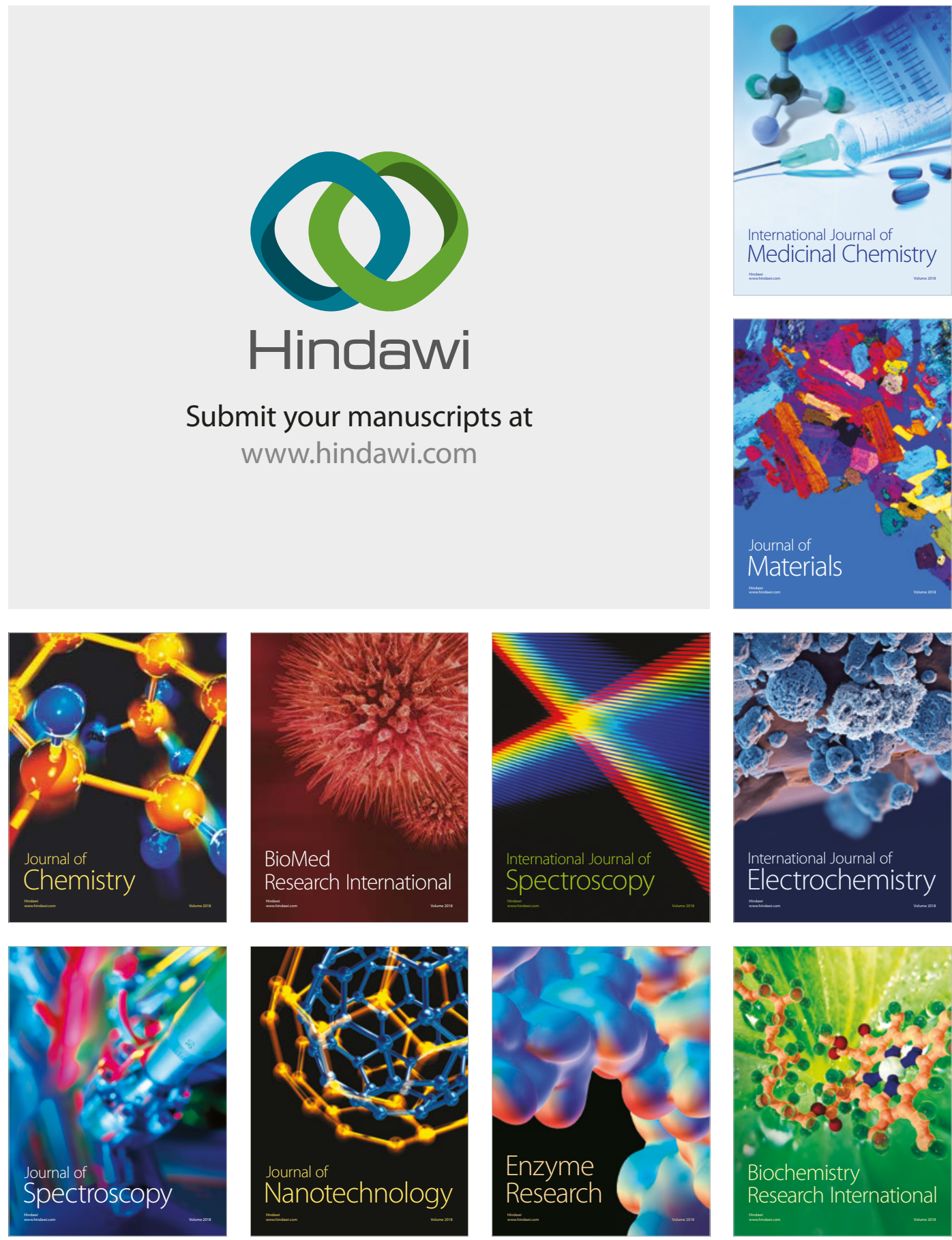
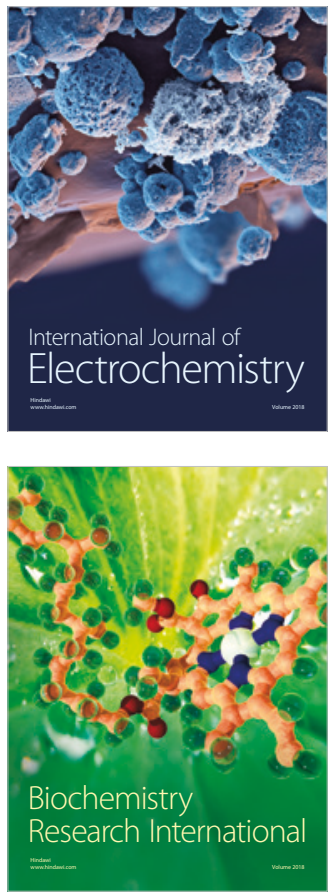